\title{
Raised serum bile acid concentrations after occupational exposure to styrene: a possible sign of hepatotoxicity?
}

\section{EDLING AND C TAGESSON}

From the Departments of Occupational Medicine and Clinical Chemistry, University of Linköping, Linköping, Sweden

ABSTRACT Fasting serum concentrations of conjugated bile acids were investigated in 23 men who had been exposed to styrene and compared with the concentrations in 60 non-exposed individuals. Eleven of the exposed subjects had raised concentrations of either cholic acid or chenodeoxycholic acid or both. There were no indications of alcohol abuse, drug intake, or undiagnosed liver disease. It is possible, therefore, that the raised bile acid concentrations were due to exposure to styrene. This would support the concept that occupational exposure to styrene may affect the liver and point to the possibility that raised serum bile acid concentrations might be a sensitive and early indicator of hepatic injury in individuals exposed to organic solvents.

The liver plays a major part in the biotransformation of environmental agents. Accordingly, the toxic effects of certain chemical agents used in industryfor example carbon tetrachloride ${ }^{1}$ and $1,1,2$, 2-tetrachloroethane ${ }^{2}$-include serious hepatic injury, and the list of potentially hepatotoxic agents is continually growing. Also, concern among exposed workers has led to a demand for laboratory tests to be used in the early diagnosis and prevention of occupational liver disease. Such tests are, for instance, serum concentrations of "liver enzymes" such as alanine aminotransferase (ALAT), aspartate aminotransferase (ASAT), and gammaglutamyl transferase $(\gamma-G T)$. These tests have been used to screen for liver damage in workers exposed to organic solvents. ${ }^{34}$ It appears, however, that the frequency of abnormal test results in such screening is low. This could be because the concern for liver injury due to solvent exposure is unwarranted, or because the commonly used laboratory tests are not sensitive enough to detect liver damage. There are reasons, therefore, to investigate the possible use of other, more sensitive and specific laboratory tests. One such test is the measurement of the serum concentrations of bile acids.

Received 17 January 1983

Accepted 18 April 1983
With an adequate assay, serum bile acid concentrations appear superior to conventional liver function tests in detecting minor hepatobiliary dysfunction. ${ }^{5}$

Recently, Axelson and Gustavsson proposed that styrene may affect the liver and that this could result in raised serum concentrations of liver enzymes. We therefore investigated the serum bile acid concentrations in subjects exposed to styrene and compared the levels with those found in healthy, unexposed individuals.

\section{Materials and methods}

Subjects-Twenty three men aged 19-58 (mean age 40) processing sewage pipes were investigated. The average duration of their exposure to styrene was 2.5 years. They had no apparent liver disease and took no drugs known to affect the liver. One of the subjects occasionally abused alcohol.

Procedures-On a Friday morning, at the end of a working week, fasting blood samples were taken, centrifuged, and frozen at $-20^{\circ} \mathrm{C}$ until analysed. On the day before environmental sampling of styrene had been performed and urine collected for analysis of mandelic acid. Exposure levels in the breathing zone-measured by personal sampling-ranged from 41 to $202 \mathrm{mg}$ styrene $/ \mathrm{m}^{3}$ air.

Analysis-Urinary mandelic acid (MA) was determined by isotachophoresis essentially as 
Table 1 Frequency of abnormal liver laboratory test results in 23 men exposed to styrene when processing sewage pipes

\begin{tabular}{llll}
\hline $\begin{array}{l}\text { Laboratory } \\
\text { test }\end{array}$ & \multicolumn{3}{l}{ Abnormal test results } \\
\cline { 2 - 4 } & Defnition* & No & $\%$ \\
\hline S-LD & $>7.5 \mu \mathrm{kat} / \mathrm{l}$ & 0 & 0 \\
S-ALP & $>5.0 \mu \mathrm{kat} / 1$ & 0 & 0 \\
S- $\gamma$-GT & $>0.7 \mu \mathrm{kat} / 1$ & 1 & 4 \\
S-ASAT & $>0.7 \mu \mathrm{kat} / 1$ & 1 & 4 \\
S-ALAT & $>0.7 \mu \mathrm{kat} / 1$ & 3 & 39 \\
S-CA & $>0.8 \mu \mathrm{mol} / 1$ & 9 & 39 \\
S-CDCA & $>1.1 \mu \mathrm{mol} / 1$ & 9 & \\
\hline
\end{tabular}

*Upper reference value given by the clinical chemistry laboratory.

described by Sollenberg and Baldesten. ${ }^{7}$ Serum aspartate aminotransferase (S-ASAT), alanine aminotransferase (S-ALAT), gammaglutamyl transferase $(\mathrm{S}-\gamma-\mathrm{GT})$, alkaline phosphatase (S-ALP), and lactate dehydrogenase (S-LD) were determined using standard analytical procedures. Fasting levels of serum cholic acid (S-CA) and chenodeoxycholic acid (S-CDCA) were determined by radioimmunoassays ${ }^{8}$ in which glycine and taurine conjugates were measured with equal sensitivity. Unconjugated CA and CDCA had cross reactivities towards the CA and CDCA antiserum of $20 \%$ and $30 \%$, respectively.

Reference values-Fasting reference values for serum bile acids were established using sera from 60 healthy fasting individuals aged 18-61 y (median age 25). As calculated from the mean $+2 \mathrm{SD}$, the upper reference values were $0.8 \mu \mathrm{mol} / \mathrm{l}$ and 1.1 $\mu \mathrm{mol} / \mathrm{l}$ for S-CA and S-CDCA, respectively. ${ }^{8}$ Table 1 gives the upper reference values for the other liver tests.

\section{Results}

Table 1 shows frequency of abnormal results in var- ious liver laboratory tests. Nine of the 23 individuals had raised fasting levels of S-CA and nine of S-CDCA, and altogether 11 had raised levels of either S-CA or S-CDCA (or both). Three subjects had raised S-ALAT and one raised S-ASAT. Only one subject showed raised S- $\gamma$-GT and none increased S-LD or S-ALP.

Altogether, 13 of the 23 subjects investigated had one or more abnormal liver laboratory test results (table 2). Thus it appeared that 10 subjects had increased levels of either S-CA or S-CDCA (or both) but otherwise normal laboratory findings. Two individuals ( $\mathrm{GH}$ and $\mathrm{MN}$ ) showed increased liver enzyme activities but normal bile acids while one (KL) had both increased S-ALAT and raised S-CA.

The urinary excretion of mandelic acid (MA) ranged from 0.3 to $17.8 \mathrm{mmol} / \mathrm{l}(3.44 \pm 3.82, \mathrm{~m} \pm$ $\operatorname{SD}(n=22))$. A correlation $(r=0.9)$ was obtained between urinary MA and styrene exposure; this is in accordance with the concept that urinary MA reflects the degree of styrene exposure..$^{9}$ According to Swedish occupational health practice, urinary MA values of $1.3 \mathrm{mmol} / \mathrm{l}$ indicate potentially hazardous styrene exposure. If this MA-value was used to dichotomise the subjects into "high exposed" and "low exposed" (table 3), nine of the ten individuals with raised bile acids were high exposed. Of the five low exposed subjects, one

Table 3 Serum bile acid concentrations in 22 men exposed to styrene when processing sewage pipes

\begin{tabular}{lll}
\hline $\begin{array}{l}\text { Bile acid } \\
\text { concentration }\end{array}$ & \multicolumn{2}{l}{ Group of individuals } \\
\cline { 2 - 3 } & Low exposed $\dagger$ & High exposed $\ddagger$ \\
\hline Raised & 1 & 9 \\
Normal & 4 & 8 \\
\hline *CA or CDCA or both. & \\
$\dagger<1.3$ mmol mandelic acid/l urine. \\
$\ddagger>1.3$ mmol mandelic acid/l urine.
\end{tabular}

Table 2 Liver laboratory test results in 13 men exposed to styrene when processing sewage pipes

\begin{tabular}{|c|c|c|c|c|c|c|}
\hline Subject & Age (y) & $\underset{(\mu k a t / l)}{S-A S A T}$ & $\underset{(\mu k a t / l)}{S-A L A T}$ & $\begin{array}{r}S-\gamma-G T \\
(\mu k a t / l)\end{array}$ & $\begin{array}{l}\text { S-CA } \\
(\mu m o l / l)\end{array}$ & $\begin{array}{l}\text { S-CDCA } \\
(\mu \mathrm{mol} / \mathrm{l})\end{array}$ \\
\hline $\begin{array}{l}\text { AB } \\
\text { CD } \\
\text { EF } \\
\text { GH } \\
\text { IJ } \\
\text { KL } \\
\text { MN } \\
\text { OP } \\
\text { QR } \\
\text { ST } \\
\text { UV } \\
\text { WX } \\
\text { YZ }\end{array}$ & $\begin{array}{l}33 \\
48 \\
21 \\
47 \\
27 \\
48 \\
34 \\
27 \\
23 \\
27 \\
23 \\
19 \\
21\end{array}$ & $\begin{array}{l}0.22 \\
0.37 \\
0 \cdot 38 \\
0 \cdot 84^{*} \\
0.36 \\
0.47 \\
0.37 \\
0 \cdot 28 \\
0.42 \\
0 \cdot 32 \\
0.30 \\
0.48 \\
0.44\end{array}$ & $\begin{array}{l}0.22 \\
0.19 \\
0.24 \\
0.96^{*} \\
0.43 \\
0.81^{*} \\
0.85^{*} \\
0.46 \\
0.22 \\
0.24 \\
0.25 \\
0.38 \\
0.14\end{array}$ & $\begin{array}{l}0.32 \\
0.43 \\
0.28 \\
0.86^{*} \\
0.28 \\
0.52 \\
0.52 \\
0.47 \\
0.22 \\
0.17 \\
0.26 \\
0.30 \\
0.24\end{array}$ & $\begin{array}{l}1 \cdot 4^{*} \\
1 \cdot 3^{*} \\
0 \cdot 9^{*} \\
0 \cdot 7^{*} \\
0.9^{*} \\
1 \cdot 3^{*} \\
0 \cdot 5 \\
1 \cdot 8^{*} \\
0 \cdot 6^{*} \\
1 \cdot 3^{*} \\
0 \cdot 9^{*} \\
0 \cdot 2^{*} \\
2 \cdot 3^{*}\end{array}$ & $\begin{array}{l}2 \cdot 3^{*} \\
1 \cdot 7^{*} \\
1 \cdot 4^{*} \\
0 \cdot 8 \\
0 \cdot 9 \\
1 \cdot 0 \\
0 \cdot 6 \\
2 \cdot 5^{*} \\
1 \cdot 3^{*} \\
3 \cdot 2^{*} \\
2 \cdot 5^{*} \\
2 \cdot 5^{*} \\
6 \cdot 9^{*}\end{array}$ \\
\hline
\end{tabular}

*Abnormal test results. 
(20\%) had raised serum bile acids. Assuming that the raised bile acids were due to styrene exposure, the bile acid test would have $53 \%$ sensitivity and $80 \%$ specificity (data from table 3 ).

\section{Discussion}

This study aimed to determine the serum bile acid concentrations after occupational exposure to styrene and to relate these values to those found in healthy non-exposed individuals. In hospital investigations of liver disease as in occupational health screening the results of laboratory tests are related to reference ranges given by the laboratory at hand. The reference values for S-CA and S-CDCA used in this study were based on samples from 60 healthy individuals in the same age span as the exposed subjects. Moreover, there are no indications that fasting serum bile acid concentrations in healthy adults are age- or sex- dependent. ${ }^{10}$ With this in mind it seems justified to use the established reference values for comparison with values found in exposed subjects rather than selecting a particular control group.

Direct measurements showed that the investigated subjects were exposed to styrene in the range of $41-202 \mathrm{mg} / \mathrm{m}^{3}$; for comparison, the current Swedish TLV is $170 \mathrm{mg} / \mathrm{m}^{3}$. Also, the urinary excretion of mandelic acid (MA) showed that the subjects were all exposed to styrene and that urinary MA excretion reflected the degree of styrene exposure. As to the general exposure level, previous studies have indicated that $100-300 \mathrm{mg} / \mathrm{m}^{3}$ may have caused raised serum levels of aminotransferases. ${ }^{6}$

The investigation showed that 13 of the 23 subjects $(57 \%)$ had one or more abnormal liver test results (table 2). Of these, only three had raised liver enzymes whereas 11 had raised bile acids. The reason for this cannot be unequivocally established, but some possibilities may be discussed.

To explain raised aminotransferase levels, alcohol consumption has always to be considered. One of the subjects $(\mathrm{GH})$ was known to abuse alcohol and he also had raised ASAT, ALAT, and $\gamma$-GT levels, but normal bile acids. As to the other subjects there were no indications of abnormal alcohol intake and $\gamma$-GT values were all normal; (the $\gamma$-GT test is claimed to be a sensitive measure of liver damage due to alcohol $\left.{ }^{11}\right)$. Even normal alcohol consumption together with styrene exposure could have affected the liver, however, since potentiation between alcohol and solvents has been shown in animal experiments ${ }^{1213}$ and in field studies. ${ }^{14}$

Other possibilities might be that the subjects did not fast to obtain proper fasting levels or that they had one or several undiagnosed liver diseases with concomitant raised bile acid levels. We have no indication, however, to support any of these contentions. None of the subjects took drugs that could have affected the liver on their own or by interacting with solvents. ${ }^{15}$ We therefore suggest that in most subjects the raised bile acid concentrations were due to their styrene exposure.

This investigation may lend further support to the concept that occupational styrene exposure adversely affects the liver. It also illustrates that routine monitoring of liver enzymes is a doubtful screening method in occupational health practice, but points to the possibility that raised bile acid concentrations might be a sensitive and early indicator of liver dysfunction.

\section{References}

' NIOSH criteria document. Recommendations for an occupational exposure standard to carbon tetrachloride. Cincinnati: Department of Health, Education and Welfare, 1975. (DHEW 76-133.)

${ }^{2}$ NIOSH criteria document. Recommendations for an occupational exposure standard to 1, 1, 2, 2-tetrachloroethane. Cincinnati: Department of Health, Education and Welfare, 1976. (DHEW 77-121.)

${ }^{3}$ Kurppa K, Husman K. Car painters' exposure to a mixture of organic solvents. Serum activities of liver enzymes. Scand $J$ Work Environ Health 1982;8:137-40.

4 Lundberg I. Liver toxicity of organic solvents. An epidemiological investigation in the Swedish paint industry. Arbete och Hälsa 1982;19:73-7. (In English.)

${ }^{5}$ Anonymous. Serum bile acid in hepatobiliary disease. Lancet 1982;ii: 1136-8.

- Axelson O, Gustavson J. Some hygienic and clinical observations of styrene exposure. Scand J Work Environ Health $1978 ; 4: 215-9$.

' Sollenberg A, Baldesten A. Analytical isotachophoresis of mandelic acid, phenylglyoxylic acid, hippuric acid and metylhippuric acid in urine after occupational exposure to styrene, toluene and xylene. J Chromatogr 1977;132:469-76.

8 Tobiasson P, Boeryd B. Serum cholic and chenodeoxycholic acid conjugates and standard liver function tests in various morphological stages of alcoholic liver disease. Scand J Gastroenterol 1980;15:657-63.

' Ikeda M, Koizumi A, Miyasaka M, Watanabe T. Styrene exposure and biologic monitoring in FRP boat production plants. Int Arch Occup Environ Health 1982;49:325-39.

${ }^{10}$ Simmonds W, Korman M, Go V, Hofmann A. Radioimmunoassay of conjugated cholyl bile acids in serum. Gastroenterology 1973;65:705-11.

"Rosalki SB. $\gamma$-glutamyltranspeptidase. Adv Clin Chem 1975; 17:53-107.

${ }^{12}$ Cornish H, Adefuin J. Ethanol potentiation of halogenated aliphatic solvent toxicity. Am Ind Hyg Assoc J 1966;27:57-61.

${ }^{13}$ Traiger P, Plaa G. Chlorinated hydrocarbon toxicity. Potentiation by isopropylalcohol and acetone. Arch Environ Health 1974;28:276-8.

${ }^{14}$ Lachnit V, Brichta G. Trichloräthylen and Leberschädigung. Zentralblatt für Arbeitsmedizin und Arbeitsschutz. Band 8 1958;3:56-62.

${ }^{15}$ Edling C. Interaction between drugs and solvents as a cause of fatty change in the liver. Br J Ind Med 1982;39:198-9. 